\title{
The Influence of Digitization on Marketing Mix: In Special Reference to Tanishq
}

\author{
Bindu Tiwari ${ }^{1}$, Dr Naveen Kumar ${ }^{2}$ \\ ${ }^{1} \mathrm{Ph} . \mathrm{D}$ Scholar, ${ }^{2}$ Assistant Professor \\ Gautam Buddha University, Greater Noida, Uttar Pradesh, India
}

\begin{abstract}
The advent of internet has made present day easy and fast from each and every aspects and dimensions. Every field is trying to come out of its best through optimal use of this invention from domestic daily goods to luxury and fashionable jewellery items too, so did marketing. No matter how unique and wonderful anything is, without communication, distribution and on time availability, it is of no worth. Digitization has channelled each component so simple and smooth. Marketing is a highly sensitive function, determining success or failure of any project in today's time. This paper tries to correlate if any noticeable relation can be traced out between digitization and marketing mix trends. Main aim of paper is to present an overview of marketing mix in relation with digitization in an individual basis with reference to marketing mix strategy of Tanisq. This paper is a review paper of remarkable thoughts presented by expert opinions already shared and available in various secondary sources of information regarding influence of digitization over marketing industry.
\end{abstract}

Key words: Advertising, digital marketing, online advertisement, marketing mix, Tanishq marketing strategy

\section{INTRODUCTION Digitalization}

The finest innovation of modern world is "Internet". Constant connectivity, contextual relevance, boundary less market and multi-screen world are changing shopping experiences of people. The pace of change before and after internet is noticeable in every sector. First choice to search answer to any question and information or solution to any problem is internet. Either, health, education, science, technology, business, inventions or history, every detail is there in it, as far as known to any of human mind. In this situation we can see highest access of internet is done in business and marketing sector. Yes internet has given a global platform to sellers and buyers too. But, buyers are given highest power to direct whole market. Yet some extra ordinary practitioners come up and regularly try to come up with more than and before anyone can expect.

Digitization is internet of goods, services, information, communication, etc. digitization made the world boundary less. Virtual networks are used by every sector to get benefited and best express own selves in most economical way. So particularly in business sector companies are being more concern with updating them with technology in any possible way. So some influence can be clearly traced out while designing marketing mix. From high-tech production system to pre promotion, demand generation, buying, selling, distributing, pricing, packaging, etc. to feedback channel all are now determined considering present global digital market.

No more only education, service and communication sector are leading to best use internet, but also very precious things have begun approaching internet for reaching to the customer, like gold, diamond, real estate, etc. We can say they don't really approach customers through internet to buy and sell, but to create some space for company positively to be the first choice in mind to prefer in need. And amazingly some companies becomes extra ordinarily able to influence its customer through amazing collaboration of marketing mix and use of internet.

\section{Tanishq}


Tanisq is the name associated with its well-known parent company Titan which is promoted by TATA Group of industries. It is a prominent jewellery brand which pioneered the concept of branded jewellery in the Indian market. Tanisq name was coined by $\mathrm{Mr}$. Xerxes Desai by two different words "Tan" and "Nishk" meaning "body" and "gold ornament" respectively. Tanisq don't treat its jewellery as a mere product but as a form of their art and quality trust. Tanisq earned a unique image which is synonyms to an artistic blend of traditional values to modern outlook with reliable quality.

\section{LITERATURE REVIEW}

Digitization started and took a speedy growth in every sector and everywhere almost. It has raised the eyebrows of concern party's about the pros and cons of it for first and then, its impact and impact strength and finally towards its utilization in behalf. So many researches are done over its impact specifically too over specific area or specific sector too. Many experts have put their views over it and many individual companies have done research over its utilization and balancing with the change.

Sumit G. Khadekar, Manish T. Wanjari \& Ramesh R. $\operatorname{Kohad}(2016)$, in their research paper mentioned the importance and reasons of investment in gold knowing benefit of various caret gold. Their findings rank Tanishq as top most brands in branded jewellery market. This paper has focused on business of traditional jewellery shop, but still highlighted the growing efforts of branded jewelleries in market. This shows positive future of branded jewels.

Arul Jyothi, Dr. S. K. Nagarajan highlighted jewellery branding as new trend of jewellery market, in their research paper recently published in 2014, in International Journal of Business and Administration Research Review. Their study shows $66 \%$ of customer prefers buying branded jewellery and majority of them noted advertisement played a significant role in choice of brand. Advertisement nowadays have obviously became digital to reach best to their target customers. Or can be said that, range of target group has become wider.

Hitesh Bhasin in his latest online article in marketing91, Marketing mix of Tanishq (2018), has mentioned specific dimensions of marketing mix of Tanishq. Additionally, according to various online sources and website of Tanishq, after digitization the sense of 4ps has been changed as different 4Ps which mostly mean to focus around single ' $P$ ' i.e. promotion. These 4Ps are, people, performance+, programmatic and platform. These all mean to focus on target people, advertisement effectiveness, and systematic way of promoting and platform to do so. Tanishq with no doubt is a leading jewellery brand, which has put its all-round effort to gain sustainable relationship with customer and cover a large group of them as target customer. Tanishq has fully tried its best to harmonize all the varied culture, traditions, generations, groups, occasions and lifestyles under one brand. And it has been truly supported by digitization of mainly communication mechanism.

Wider spread use of internet has enabled company to cover wide enough with the same theme. Herein survey sampling site, it mentions that, not only onto other 4Ps, but also marketing mix has been transformed to $4 \mathrm{Cs}$, i.e. consumer, cost, communication and convenience.

\section{LITERATURE GAP}

Not more study has been found about the impact of digitization over marketing specifically of Tanishq or any company, but it has enough study in general. Series of emotional ads are good examples of this effect. Long length story telling content of ads, full wide screen displays all around, many pop-ups and blinks regarding brand, various shopping sites including home page to put an order or give feedback, virtual displays with numerous designs available at a time, etc. are all examples again of the impact that digitization has shown in marketing mix of Tanishq. After reviewing 25 different online research papers and consulting other various online sources, it gives conclusion that digitization has obvious impact on every sector more or less, but jewellery industry is supposed to be very sensitive and relies mostly over trust, accuracy, quality, security, relationship building, after sales assurance, reparability and re-sale-ability. In this case, jewellery brand has less scope to sell product online but it becomes able to occupy some space in minds of customer. It can at least offer the best options, sufficient information, virtual windowshopping, comparison, exclusive promotion and best communication.

\subsection{RESEARCH OBJECTIVE}

Main aim of this paper will be to find the impact of digitization on marketing mix of Tanishq. So focus of this paper will be to study individual elements of $4 \mathrm{ps}$ 
before being influenced by digitalization and after considering digital promotion and competition.

\section{RESEARCH METHODOLOGY}

This paper is a conceptual paper and majorly based on secondary sources of data. It has been gone through depth observation of its online and other means of marketing. Various occasional, festive and other schemes, reliable quality measurement of purity of gold and diamonds, pricing targeting very low range to high range luxurious fashionable designer jewellery, etc. shows that it is a very conscious brand who is exploiting the modern digital technology not only in promoting but also in designing, distributing, producing, pricing and such over all aspects.

To reach up to depth of these objectives, various ad campaigns of Tanisq both online series and off line hoardings are analysed from the year 2012-2017. Various research papers and articles published during same five years are also studied to understand its trend.

\section{MARKETING MIX IN RELATION WITH DIGITALIZED MARKETING}

Tanisq is a well-recognized and a trusted brand for purity and originality of its product. It deals with both traditional and fashionable range of product. With the growing market of gold and jewellery, being a pioneer company to present branded jewellery, it is not merely conscious of market competition but also it has becomen a competition creator. Tanisq deals with all sorts of fashionable jewellery, which not only welcomes all new modern styles but also don't let classical style be faded out of trend. In this regard let us see its marketing mix in relation with digitalized marketing preference in present Indian market.

\section{4ps of marketing mix of Tanisq in relation to digitalization}

\subsection{Product in marketing mix of Tanisq}

Product importance before and after has remained the same but after digitization product is added with product buying experience. Very sensitive jewellery also lacks physical touch actual looks and trial, but with it customer gets a huge option and unlimited time to explore number of options at their convenient time. This is how Tanishq first ' $\mathrm{P}$ ' as product from marketing mix been affected. Let us see it in brief about the product of it:

\subsubsection{Product Variety:}

Tanisq is a pioneer brand which initiated the measurement of purity of gold and thus gained trust over purity and reliability of jewellery quality. It started its US and European designs with 18carat ornaments which didn't get much popularity thus Tanishq started using 22kt gold for its most of ornaments. Product ranges from covering traditional and cultural style to matching present day fashionable lifestyle. Pure gold artistically designed with diamonds and coloured gems makes its design wow. It covers all sets of jewellery i.e. finger rings, nose pins, bangles, mangalsutra, necklace, ear rings, pendants, bracelets, gold coins, bars, etc. Not only product type but also variety of options under one product type, like under nose pin they will offer various type of nose pin, only gold, diamond nose pin, coloured, shapes of nose pins, thickness, price range, etc.

\subsubsection{Brand Variety:}

Main attractions of its product are by names of following:

1. Inara

2. Iva

3. Zuhur

4. Mehek

5. Limited edition

6. Divyam

7. Uttara

8. Niloufer

9. " Mismatch

10. Amara

11. Queen of hearts

12. Subham

13. Fine lines

Digitization has influenced its product designs too. Tanishq has used online marketing in order to analyse the jewellery trend, it also works on order, mechanised designs, automated measurement and product handling and security of showrooms. Over 3500 designs were offered by in-house designers in Tanishq which is regularly changed on the basis of time, occasion and feedback from customers.

\subsubsection{Design Variety:}

Tanishq designs are all not merely simple design but also the team work of award winning designers. It is all known for its specialized design collection and as a design leader in the jewellery market. Tanishq is positioned to be the only brand to have full-fledge 
design studio with the largest designer teams who regularly explore unique set of design to cover specialized series like festival, particular marriage tradition, particular tradition of some place specific and ongoing work life matching designs and so on.

\subsubsection{Service:}

No company can solely lead market with its quality aspect only when it lacks customer satisfaction. Tanishq has been so conscious of its customer after sales services too. Encouraging repetition of purchase, positive word of mouth and overall responsibleness, it guarantees return, exchange and sale of jewellery. It also ensures free repair from any Tanishq showrooms all over India. Sales and exchange is made reliable using carat meter and reasonable exchange or sales rate. Customers are offered with low starting rate as low as Rs.600 also.

\subsection{Place in the marketing mix of Tanishq}

Visibility in digital market depends on position at which brand appear in search engine ranking pages. It may be paid or may be due to its popularity or its presence in social media. Tanishq is a global brand focusing over European and American market designs initially but later it spread its market in domestic level too. It has started its market from Chennai but today it owns more than 170 retail and showrooms all over India till 2016. Its overseas pilot stores are located in New Jersey and Chicago and domestically it is headquartered in Bengaluru in Karnataka.

Tanishq serves a good and planned channel of its retail and big showrooms where it comprises six large format outlets of more than 15000 sq. feet. It has its showrooms fully owned and some franchised ones mostly located in high profile areas. Tanishq used digitization by starting an online portal to display its design, various social media with designs and unique trends it regularly tries to lead, online order and feedback too.

\subsection{Price in the marketing mix of Tanishq}

Price can be said as least affected 'P' among 4Ps after digitization also. But it may come up with various occasional offer and price schemes due to market competition and probability of comparison. Though Tanishq targets upper and upper-middle class women as its customer, it also keeps choice of lower price and frankly low carets gold and jewellery who yet wants to feel good wearing Tanishq. Tanishq is a brand synonym to power, prestige and purity of quality.
People who can afford it also want to pay for it. So pricing strategy of it is premium pricing. Tanishq is one of fastest growing brand with its sales from retail of more than 10000 Crores.

For pricing, it has used online facility to openly classify price of each item on some range as per its quality through online display of design and price. A range of INR.399 also started to significantly cut the barrier of price to enter lower class income customer group to Tanishq stores. It used its online portal to present best offers and styles in preferred price of customer, that customer can themselves filter from portals.

\subsection{Promotion in the marketing mix of Tanishq}

Promotion ' $\mathrm{P}$ ' is most affected and updated ' $\mathrm{P}$ ' after digitization. It has best used this digital facility to outreach as much mass as possible and in the way best possible.

Tanishq is Tanishq today not merely due to its product quality and design, but also due to its successful communication that made its target customer aware of the difference that Tanishq is standing with. It has exploited all possible mediums of promotion from print media (billboards, hoardings, newspaper, magazines, etc.) to online media (own portal, social media, pop ups and websites) IT is also very famous for its emotional and positive audiovisual ad campaigns. Tanishq been always aware of celebrity power and Deepika Padukon endorsed it.

Various Bollywood movies used its all set of some typical trendy jewells like in Jodha Akbar, Paheli , and Ramleela Even it has offered gold of worth 20 crore to the buyers of Maruti, by which both the company got benefited in 1999.It conducted various fashion shows to create different shopping experience of jewellery and it has played a vital role to harmonize various ethnic culture all together under same brand umbrella. Various exchange offers of exchanging impure gold with 22 caret pure gold ornament helped Tanishq attract customer for transparent quality choice offer. This campaign promoted Tanishq so positively that it positioned for quality and trust.

It developed a first gold gifting scheme in its ads in around 1998. Its theme was "when you want to say thank you, say it in gold", various customer contact programme, various occasion specific gifting range, relation specific, place specific, tradition specific and 
all are separately presented in various ad campaigns. Various loyalty reward programmes, occasional schemes, Golden Harvest Saving for making customer realize that Tanishq cares for you and promoted gold purchase as investment not expenses. It's emotionally and beautifully ran ad campaigns positively delivers all that it wanted their customer to feel and understand about them. Recently one ad promoting re-marriage got viral in media. From various promotional strategy Tanishq seems to be conscious of creating harmony, equality and justice in society.

\section{FINDINGS}

Digitization has spread its influence in core, like everywhere from daily life to behaviour and mentality of people. The same people are target customers of different markets. So every company must be updated with more than customers expect and before they question to the company and its strategy. The lifestyle, busy routine, fast market and competition have invited best platform i.e. internet, where people can do as they want at the time they want and from the place they want. But to the complexity of digitization, marketers has to be more sensitive towards demonstrating and promising anything because here customers can't physically see, touch and feel product but at same time have number of choices to compare with.

Market is the place where we can experience the drastic effect of digitization. Market crowd, buying behaviour, customer expectation, frequency and timing are all changed. The same way companies have to moderate them. Marketing mix is all about those elements which help to develop marketing plan. Major marketing mix for product was 4Ps, i.e. Product, place, price and promotion. Additionally for service, there adds 3Ps more, i.e. People, Process and physical evidence. But now after digitization, various transformations can be seen in each marketing mix component but promotion is the ' $\mathrm{P}$ ' which is maximum influenced and price is the ' $\mathrm{P}$ ' which can be said less influenced among them.

\section{CONCLUSION}

Digitization came up with various opportunities but at the same time it has added complications due to its virtual nature where customer suspects in lack of physical touch, view and feel. So Tanishq being more sensitive as a jewellery brand, it has a lot of responsibility to keep its promise of quality and purity with transparency. Yet Tanishq has used this medium in its behalf positively. It has focused on investment aspect, sentimental aspect with low to high range products, highly diverged range of jewellery collection under one site and also in showroom such that it harmonically unite various traditional, cultural and place specific jewellery trend at one place. Tanishq has developed its marketing mix in such a way that it can fully get benefited of digital technology to design, distribute and promote at minimum investment with maximum coverage. The best part is promotion. It has come up with maximum ways to deliver its regularly creative designs which always match with the need of time, place, occasion and different lifestyle.

As per the objective of our study, we come up to the conclusion that Tanishq for being the first name in jewellery market to be trusted for its purity, quality, variety, reliability and long term promised responsibility is a combine effort of loyal quality, continuous creativity, best international designers team, possible exploitation of online opportunity to communicate and focus on customer satisfaction. Purchase of jewellery is based upon price, quality and design apart from different social and cultural occasions. Customers mostly ladies group are associated with jewellery shopping but before that they go up with a lot of window shopping and comparisons, which is all assisted by digitization more conveniently. Thus, understanding these all aspect, Tanishq has initiated gifting range, low price range, high quality and designer range, ethnic and modern range which can be easily even purchased and understood by male members. At the same time through its audio-visual ads it convinced male customers also to initiate jewellery purchase to make their special one more special. Additionally, emotional ad series of Tanishq encouraged making gold purchase a big decision. Through its ad campaign 'Say thank you with gold', it tried to simplify jewellery purchase and offering low price range starting at minimum price of Rs.600 and even diamond starting at Rs.2000. It will help customer get away from the fear of entering well-fledge showrooms of Tanishq and provide the opportunity of getting all in one and don't let other options to revolve around the mind of customer.

\section{REFERENCES}

1. Digital Media Transforming the Marketing Mix (https://www.surveysampling.com/blog/digitalmedia-transforming-the-marketing-mix/) 
2. Impact of digitalization on business communication,(https://www.slideshare.net/hema nthcrpatna/a-marketing-project-report-on-tanishq)

3. Arul Jyothi and Dr. S. K. Nagarajan, Jewellery branding: A new trend, International journal of business and administration research review, 2014

4. Sumit G. Khadekar1, Manish T. Wanjari \& Ramesh R. Kohad, "Study of Consumer Buying Behavior between Branded \& Non-Branded Gold Jewellery in Vidarbha Area of Maharashtra State" Quest journals, journals of research and management, 2016
5. Mirjana Tankosic, Dragana Trifunovic, "The Influence of Digitization and New Media on the system of Companies Marketing communication, consumers and business Enterprises", Advances in environmental science and energy planning.

6. Jordan weissmann, "We have no idea If online Ads work", Slate magazine, 2017

7. Geoffrey Precourt, "How Neurological measures work in advertisement", journal of advertising research, 1st june, 2016

8. Werner Reinartz and Peter Saffert, "Creativity in advertising: when it works and when it doesn't", Harward Business Review, june 2013

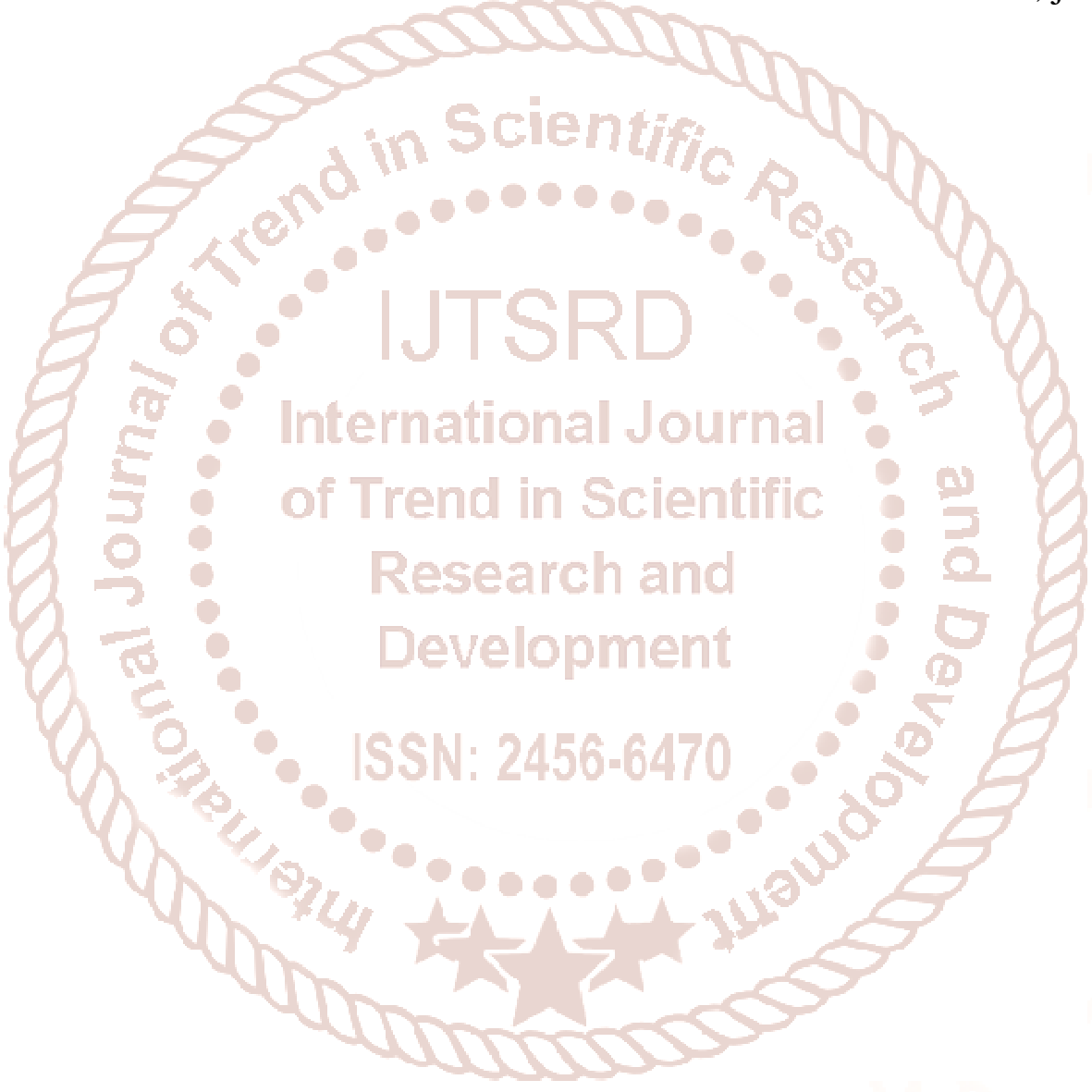

